\title{
PENINGKATAN AKSESIBILITAS DENGAN PEMBANGUNAN JARINGAN JALAN RING ROAD DI KOTA TANJUNG SELOR
}

Yopi Juansyah Abdulrahman Sekolah Tinggi Transportasi Darat Jalan Raya Setu Km. 3,5 Cibuntu, Cibitung, Bekasi, Jawa Barat Telp: 021-8254640

\author{
Efendhi Prih Raharjo \\ Dosen \\ Sekolah Tinggi Transportasi \\ Darat Jalan Raya Setu Km. \\ 3,5 Cibuntu, Cibitung, \\ Bekasi, Jawa Barat Telp: \\ 021-8254640
}

\author{
Siti Umiyati \\ Dosen \\ Sekolah Tinggi Transportasi Darat \\ Jalan Raya Setu Km. 3,5 Cibuntu, \\ Cibitung, Bekasi, Jawa Barat Telp: \\ 021-8254640
}

\begin{abstract}
Tanjung Selor city is has economic growth that very high with was building land use area for urban area and sub urban area. That was need integrated to regulation transport system to do priority has been support accessibility person of dailiy activities that was building ring road with can purpose analysis performance of the road network to was building land use with support that effective and eficient transportation system. That was building using method of the ring road network is to identify the problem, transport modeling, forcasting transport, and traffic assignment. The condition of the performance road network with freemoving 192,5 vehicle-hour, 0 delay second/smp. Distance travelled 6815,8 vehicle-km, overall network speed 23,6 km/hour, and fuel consumption 1730,6 litres .
\end{abstract}

Keywords: Land Use, accessibility, transport modeling, forcasting transport, traffic assignment.

\begin{abstract}
ABSTRAK
Kota Tanjung merupakan kota yang mengalami pertumbuhan ekonomi yang sangat pesat dengan perkembangan tata guna lahan yang sangat tinggi baik untuk daerat pusat kota mapun daerah pinggiran kota. Berkaitan dengan hal tersebut perlu adanya penataan sistem transportasi yang perlu dilakukan terutama dalam menunjang aksesibilitas seseorang dalam melakukan kegiatan sehari-hari dengan pembangunan jaringan jalan ring road dengan tujuan untuk melakukan analisis terhadap kinerja jaringan jalan terhadap rencana pengembangan tata guna lahan dalam mendukung sistem transportasi yang efektif dan efisien. Metode yang digunakan dalam pembangunan jaringan jalan ring road tersebut adalah dengan mengidentifikasi permasalahan secara langsung, pemodelan transpotasi, peramalan transpotasi, dan pembebanan perjalanan. Kondisi eksisting dari segi unjuk kinerja lalu lintas dengan pergerakan lancar 192,5 kendaraan-jam, antrian 0 detik/smp, panjang perjalanan 6815,8 kendaraan-km, kecepatan perjalanan23,6 km/jam, dan BBM perjalanan 1730,6 liter.
\end{abstract}

Kata Kunci: Tata Guna Lahan, Aksesibilitas, Pemodelan Transportasi, Peramalan Transportasi, Pembebanan Perjalanan 


\section{PENDAHULUAN}

Transportasi merupakan suatu bagian penting dalam kehidupan, dengan adanya transportasi dapat memindahkan orang atau barang dari suatu tempat ke tempat lain dan fungsi utamanya adalah menghubungkan manusia dengan tata guna lahan. Dengan adanya transportasi maka perlu adanya jaringan jalan sebagai prasarana untuk memindahkan orang atau barang tersebut dengan tujuan untuk mendorong pertumbuhan ekonomi, sosial, budaya dan stabilitas nasional, serta upaya pemerataan dan penyebaran pembangunan terutama di Kota Tanjung Selor.

Kota Tanjung Selor merupakan salah satu kota yang terletak di provinsi Kalimantan utara yang sedang mengalami pertumbuhan cukup tinggi baik pertumbuhan ekonomi, pertumbuhan pembangunan, maupun pertumbuhan infrastruktur jalan karena Kota Tanjung selor menurut dokumen review RTRW Kabupaten bulungan Tahun 2005 dalam konteks regional menetapkan bahwa Kota Tanjung Selor termasuk kedalam hirarki 1 yang artinya merupakan kawasan perkotaan dengan fungsi sebagai pusat pertumbuhan utama dan Pusat Kegiatan Wilayah (PKW) dengan orientasi kegiatan berupa pemerintahan, perdagangan, pertambangan, industri dan pelayanan masyarakat serta sebagai pintu gerbang perdagangan keluar wilayah Kota Tanjung Selor dengan kelengkapan sarana dan tingkat pertumbuhan penduduk yang cukup tinggi. Sedangkan dalam konteks lokal Kota Tanjung Selor memiliki pusat kegiatan kota yang menjadi titik-titik konsentrasi elemen pembentuk ruang kota dan pusat sub urban yang memiliki elemen pembentuk tambahan ruang kota.

Berdasarkan konteks regional dan lokal yang diiringi dengan pertumbuhan Kota yang tidak disertai dengan perencanaan transportasi yang mendukung urat nadi perputaran kegiatan perekonomian maka akan berdampak pada menurunnya kinerja pelayanan transpotasi pada masa sekarang dan masa yang akan datang. Untuk mengantisipasi hal tersebut maka perlu adanya penataan transportasi perlu dilakukan, terutama dalam segi jaringan jalan untuk menunjang semua kegiatan yang dilakukan masyarakat Kota Tanjung Selor dan meningkatkan Aksesibilitas antar wilayah agar lebih mudah dan terjangkau dengan pembangunan jaringan jalan ring road di kota tanjung selor yang diiringi dengan adanya pengembangan Tata Guna Lahan (TGL) antara lain adanya zona industri, pengembangan Bandar udara, pengembangan sub terminal 1 (TOD), pengembangan zona wisata theme park (pusat kebudayaan), pengembangan zona hotel dan restoran, zona pusat pemerintahan kabupaten/kota dan pemerintahan provinsi, zona high income residential, pengembangan zona wisata theme park 2 (Taman Kota), zona sub terminal 2 (TOD) dan pengembangan infrastruktur termasuk jaringan jalan yang dapat menggambarkan keberhasilan pembangunan, khususnya pembangunan ekonomi yang berkualitas. 


\section{TINJUAN PUSTAKA}

\section{Sistem transportasi}

Sistem menurut Ofyar Z Tamin adalah gabungan dari beberapa komponen atau obyek, yang saling berkaitan satu dengan yang lainnya. Dalam setiap sistem organisasi perubahan pada satu komponen akan menyebabkan perubahan pada komponen lainnya.

\section{Jaringan jalan}

Jaringan Jalan menurut max webber adalah satu kesatuan jaringan jalan yang terdiri atas sistem jaringan primer dan sistem jaringan Jalan sekunder yang terjalin dalam hubungan hierarkis.

\section{Aksesibilitas}

Aksesibilita menurut max adalah suatu ukuran kenyamanan atau kemudahan mengenai cara lokasi tata guna lahan berinteraksi satu sama lain dan mudah atau susahnya lokasi dicapai melalui system jaringan transportasi.

\section{Pembebanan perjalanan}

Pembebanan perjalanan menurut Ofyar Z Tamin adalah tahap pembebanan perjalanan memerlukan data masukan berupa matrik asal dan tujuan perjalanan, kapasitas jalan, dan karakteristik jaringan seperti jarak dan waktu tempuh antar zona. Matrik yang dibebankan berbentuk perjalanan perjam atau smp (satuan mobil penumpang) perjam. Bentuk keluaran dari proses pembebanan ini berupa arus kendaraan tiap ruas atau biaya dan waktu tempuh perjalanan.

\section{V/C ratio}

V/C Ratio merupakan salah satu unjuk kerja lalu lintas yang digunakan untuk mengukur suatu perbandingan antara volume lalu lintas dari survei pencacahan lalu lintas terklasifikasi dengan kapasitas ruas jalan tersebut.

\section{Total kendaraan/jam}

Total kendaraan/jam merupakan hasil perkalian antara volume kendaraan (smp/jam) yang melewati satu titik dalam kondisi tertentu yang dibutuhkan untuk menempuh ruas jalan tersebut.

\section{Total kendaraan-km}


Total kendaraan-km merupakan total pergerakan perjalanan dalam satuan kendaraan dikalikan dengan jarak tempuh.

\section{Antrian}

Antrian adalah Banyaknya jumlah kendaraan yang antri dalam suatu pendekat simpang kemudian dihitung berapa panjang antrian dari jumlah kendaraan yang berada dalam suatu pendekat tersebut.

\section{Tundaan}

Tundaan adalah waktu tempuh tambahan yang diperlukan untuk melalui simpang apabila dibandingkan lintasan tanpa melalui suatu simpang.

\section{Kecepatan}

Kecepatan perjalanan adalah kecepatan yang diperlukan untuk menempuh suatu jarak tertentu dalam waktu tertentu, termasuk perlambatan karena adanya hambatan di jalan (kemacetan, kendaraan membelok, pejalan kaki).

\section{PEMBAHASAN}

\section{Data}

Dalam pembuatan penelitian ini diperlukan data yang mendukung tujuan akhir terhadap penyelesaian masalah di Kota Tanjung Selor. Data yang diperlukan ini meliputi data sekunder yang diperoleh dari instansi-instansi terkait dan data primer yang diperoleh dengan cara survei langsung ke lapangan. Berikut merupakan data yang dibutuhkan dalam proses analisis antara lain :

1. Data Sekunder

Data sekunder yang terkait dengan perencanaan transportasi dapat diperoleh dari

a. Peta Tata Guna Lahan Terbaru dari bappeda ( Badan Perencanaan Pembangunan Daerah ) Setempat.

b. Data Kependudukan (jumlah penduduk ,jumlah keluarga/rumah tangga) dari kantor Kependudukan dan Catatan Sipil Setempat.

c. Data Jaringan Jalan dari Dinas Pekerjaan Umum Dinas Perhubungan.

d. Data Rencana Tata Ruang Wilayah (RTRW) dan Data Rencana Detail Tata Ruang ) dan Rencana Detail Tata Ruang (RDTR)

e. Data kota/kabupaten dalam angka.

\section{Data Primer}

Data primer ini merupakan data yang diperoleh langsung dari survei di lapangan, yaitu survei pencacahan lalu lintas terklasifikasi, survei gerakan membelok terklasifikasi, survei inventarisasi ruas dan simpang, survei tata guna lahan dan survei asal tujuan perjalanan. 


\section{Analisis data}

\section{Kondisi jaringan jalan jahun 2015 (eksisting)}

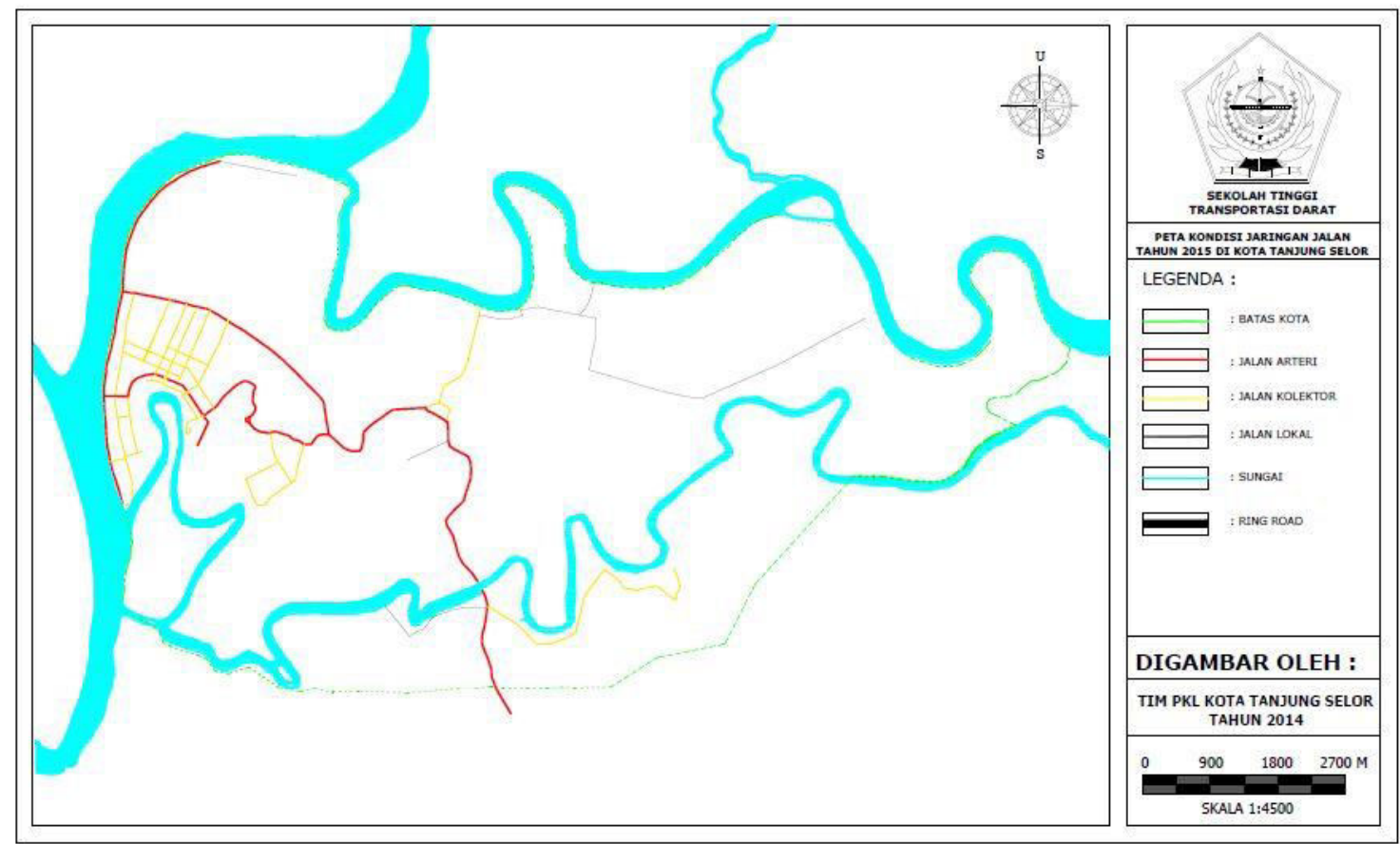

Gambar 1 : Kondisi Jaringan Jalan Tahun 2015 (Yopi, 2015)

Kota Tanjung Selor memiliki keseluruhan panjang jalan sebesar 43,207 Km. Kondisi Jaringan Jalan di Kota Tanjung Selor tahun 2015 memiliki jaringan jalan grid. Kondisi jaringan jalan tersebut digunakan untuk pembebanan perjalanan pada tahun eksisting. Pembebanan perjalanan merupakan tahap akhir dalam pembuatan model transportasi, yang sekaligus merupakan pembebanan perjalanan yang dibangkitkan oleh tiap-tiap zona ke zona tujuan melalui ruas jalan sesuai dengan moda yang digunakan sehingga membentuk suatu jaringan transportasi. Berikut Merupakan hasil pembebanan perjalanan pada tahun 2015 :

Tabel 1: Hasil Pembebanan Perjalanan Tahun 2015 (Eksisting) 


\begin{tabular}{|c|l|c|c|}
\hline NO & PARAMETER & JUMLAH & SATUAN \\
\hline 1 & Pergerakan lancar & 192.5 & Kendaraan-jam \\
\hline 2 & Arus yang tertunda & 0 & Detik/smp \\
\hline 3 & Panjang perjalanan & 6815.8 & Kendaraan-km \\
\hline 4 & Kecepatan rata-rata & 23.6 & Km/jam \\
\hline 5 & BBM perjalanan & 1730.6 & Liter \\
\hline
\end{tabular}

\section{Kondisi jaringan jalan tahun 2027 (rencana)}

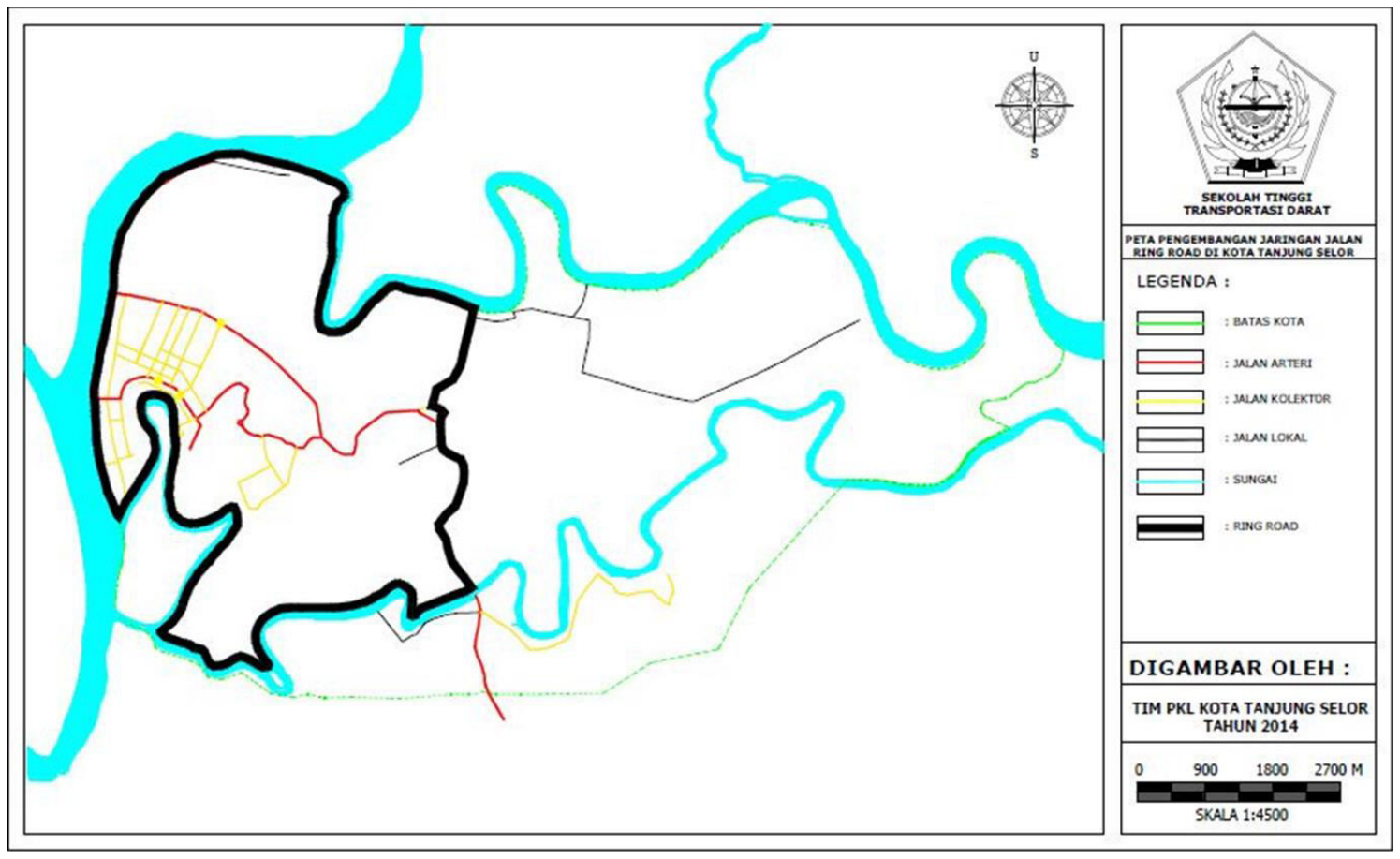

Gambar 2 : Kondisi Jaringan Jalan Tahun 2027 (Yopi, 2015)

Rencana pengambangan jaringan jalan ring road di Kota Tanjung Selordengan panjang jalan $8 \mathrm{~km}$ dengan tujuan agar memecah konsentrasi kendaraan yang masuk ke pusat kota terutama kendaraan yang berkapasitas besar dan meningkatkan nilai produktifitas. Batasan perencanaan jaringan jalan Ring Road di Kota Tanjung Selor adalah peencanaan jalan yang akan dibangun itu meyusuri tepian sungai kayan. Pengembangan jaringan jalan ring road tersebut melewati beberapa ruas jalan yaitu dimulai dari dermaga kayan 2 antara lain :
a. Jalan sabanar lama
b. Jalan mayjen katamso
c. Jalan sudirman
d. Jalan akbar 
e. Jalan hasanudin

f. Jalan cikditiro

g. Jalan sultan hasanudin

h. Jalan jelarai segmen IV

Kriteria rencana pengembangan jaringan jalan ring road di Kota Tanjung Selor antara lain :

a. Kecepatan rencana paling rendah adalah $60 \mathrm{~km} / \mathrm{jam}$ dengan lebar jalan tidak kurang dari 11 meter

b. Kapasitas jalan yang besar dari volume lalu lintas harian rata-rata

c. Lalu lintas jarak jauh tidak boleh terganggu oleh lalu lintas dan kegiatan lainnya artinyatidak boleh adanya hambatan samping di sekitar pengembangan jaringan jalan ring road tersebut

d. Jumlah jalan akses masuk dibatasi sehingga arus lalu lintas pada ruas jalan tersebut tidak terganggu dari kecepatan rencana jalan

e. Perlu adanya pengaturan tertentu jika bertemu dengan persimpangan untuk dapat terpenuhnya kecepatan dan kinerja ruas jalan

f. Rencana pengambangan jaringan jalan ring road tidak boleh terputus walaupun melalui kota.

Berikut Merupakan hasil pembebanan perjalanan pada tahun 2027 tanpa adanya pembangunan jaringan jalan ring road di kota tanjung selor :

Tabel 2: Hasil Pembebanan Perjalanan Tahun 2027 Tanpa Adanya Pembangunan Jaringan Jalan Ring Road Di Kota Tanjung Selor (Eksisting)

\begin{tabular}{|c|l|c|c|}
\hline NO & PARAMETER & JUMLAH & SATUAN \\
\hline 1 & Pergerakan lancar & 665.7 & Kendaraan-jam \\
\hline 2 & Arus yang tertunda & 0 & Detik/smp \\
\hline 3 & Panjang perjalanan & 16423.8 & Kendaraan-km \\
\hline 4 & Kecepatan rata-rata & 13.9 & Km/jam \\
\hline 5 & BBM perjalanan & 5097.8 & Liter \\
\hline
\end{tabular}

Tabel 3: Hasil Pembebanan Perjalanan Tahun 2027 Dengan Adanya Pembangunan Jaringan Jalan Ring Road Di Kota Tanjung Selor (Rencana) 


\begin{tabular}{|c|l|c|c|}
\hline NO & PARAMETER & JUMLAH & SATUAN \\
\hline 1 & Pergerakan lancar & 399 & Kendaraan-jam \\
\hline 2 & Arus yang tertunda & 0 & Detik/smp \\
\hline 3 & Panjang perjalanan & 14102.1 & Kendaraan-km \\
\hline 4 & Kecepatan rata-rata & 22.5 & Km/jam \\
\hline 5 & BBM perjalanan & 4581.2 & Liter \\
\hline
\end{tabular}

\section{KESIMPULAN}

Berdasarkan hasil analisis dengan pembangunan jaringan jalan ring road di kota tanjung selor maka dapat disimpulkan bahwa pembangunan jaringan jalan ring road di kota tanjung selor dapat mengurangi dan menguraikan permasalahan lalu lintas seiring dengan perkembangan tata guna lahan baik daerah pusat kota maupun pinggiran kota (sub urban), dan rencana pembangunan jaringan jalan ring road di kota tanjung selor dapat dibangun pada tahun 2027 karena tahun 2027 merupakan tahun yang tepat dalam pembangunan jaringan jalan ring road dan terbukti dengan adanya panjang perjalanan yang meningkat dan kecepatan yang turun pada tahun 2027 tersebut.

\section{DAFTAR PUSTAKA}

1. Azwansyah, Heri (2009). Pengembangan Jaringan Jalan di Kecematan Kapuas Kabupaten Sanggau dengan menggunakan metode multi kriteria. Jurnal Teknik Sipil UNTAN: Pontianak.

2. LPM-ITB (1997). Pengembangan Jaringan Jalan Tol dalam Kota Bandung. Lembaga Pengabdian kepada masyarakat: ITB.

3. Ali, Nur (2012). Studi Pengembangan Jaringan Jalan di Kabupaten Pinrang Sulawesi Selatan. Jurnal Teknik Sipil Universitas Hasanudin: Makasar.

4. Saputro, Dian Agung (2011). Evaluasi Kondisi Jalan dan Pengembangan Prioritas Penanganan Jaringan Lalu Lintas di Kabupaten Malang. Jurnal Teknik Sipil Brawijaya: Malang.

5. Tamin, Ofyar Z (2008). Perencanaan, Pemodelan dan Rekayasa Transportasi. Edisi ke-2: Bandung. Penerbit ITB

6. Bernaldy, (1997) Manual Kapasitas Jalan Indonesia (MKJI). Direktorat Jenderal Bina Marga dan Direktorat Bina Jalan Kota. Jakarta Selatan 
